\title{
Las conferencias episcopales en una eclesiología de comunión y participación
}

\author{
Ronaldo Muñoz, ss. cc. \\ Santiago de Chile.
}

\section{El "problema" de las conferencias episcopales}

Las dudas y los cuestionamientos levantados en los últimos afios respecto de la autoridad y el stotus teológico de las conferencias episcopales, se plantean desde dos preocupaciones a menudo convergentes, en cuanto estas conferencias traerían una amenaza, por un lado, a la autoridad suprema del papa en la Iglesia universal', y, por otro lado, a la autonomía de cada obispo como pastor de la Iglesia diocesana ${ }^{2}$.

Secundariamente, se ha planteado cambién la preocupación por una excesiva burocracia en los organismos permanentes de esas conferencias, la que por una parte absorberla a los obispos en tareas especializadas que los alejarían del pastoreo personal, y por otra parte traería una "inflación" de los roles de funcionarios eclesiásticos subalternos, quienes podrian tener más poder real que la misma asamblea de los obispos ${ }^{3}$.

De allí, las reservas y los cuestionamientos frente a toda instancia colectiva intermedia (que no sea meramente consultiva) entre la autoridad del papa y la del obispo diocesano. Así como también, y consecuentemente, entre el obispo y el párroco, y entre éste y sus "feligreses".

Sin embargo, los riesgos de la burocracia se dan también en la curia romana y las curias diocesanas. La primera puede "interponerse" entre el papa y los obispos, y, la segunda, entre el obispo y la Iglesia diocesana. Así como -en lo más cotidiano- las oficinas y equipos parroquiales pueden interponerse entre los fieles y el cuidado ("cura") y la conducción pastorales del pároco y sus vicarios.

Por otra parte, lo que suele suceder con las curias y oficinas, puede darse más en general, woda vez que el pastor (en cualquier nivel de la Iglesia) se hace informar y aconsejar por círculos confidenciales y cerrados, al margen de las 
correspondientes instancias pastorales colectivas (episcopales, presbiterales o laicales).

Más profundamente, parecen aflorar aquí estas dos preocupaciones: por un lado, la de obispos que - por su formación teológica, su espiritualidad y su práctica - están más hechos para obedecer a Roma y mandar en sus dióccsis que para asumir su corresponsabilidad en los ámbitos nacional, continental y universal, mediante el discernimiento comunitario y el trabajo en equipo con sus pares en el episcopado; y por otro lado, la preocupación de altos funcionarios de la curia romana, que quisieran volver a una forma pre-conciliar de conducir desde el centro a las iglesias particulares, con sus respectivos obispos considerados uno por uno como inmediatamente subordinados a los dicasterios romanos.

De hecho, las reticencias frente a las conferencias episcopales - las nacionales y permanentes, y las latinoamericanas desde 1968 en Medellín- han venido principalmente de obispos de mentalidad conservadora y estilo autoritario; y los cuestionamientos más explícitos y sistemáticos, de teólogos de tendencia tradicionalista y funcionarios de la curia romana.

Recordemos, por ejemplo, estas afirmaciones del cardenal Ratzinger: "las conferencias episcopales no tienen una base teológica, no forman parte de la estructura imprescindible de la Iglesia tal como la quiso Cristo; solamente tienen una función práctica, concreta... Ninguna conferencia episcopal siene, en cuanto tal, una misión de enseñanza; sus documentos no tienen un valor especílico, sino el valor del consenso que les es atribuido por cada obispo"4.

Pero las conferencias episcopales nacionales han sido reconocidas y establecidas en la Iglesia universal por el Concilio Vaticano II, en el contexto de la responsabilidad colegial de los obispos, e institucionalizadas por el derecho canónico ${ }^{6}$. Por eso, tales cuestionamientos deben proceder con una interpretación resurictiva, tanto de la doctrina teológica del concilio sobre la colegialidad episcopal, como de la autoridad de esas conferencias reconocidas por el derecho.

Así, en el nuevo código, Ratzinger subraya que las conferencias episcopales "no pueden actuar en nombre de todos los obispos, a no ser que todos y cada uno hubieran dado su propio consentimiento" o que se trate de materias "ya establecidas por el derecho común o cuando así lo establezca un mandato especial de la Sede Apostólica"'.

Y respecto de la colegialidad de los obispos enseñada por el Concilio, esos teólogos la definen rígidamente como algo indivisible que o se da en plenitud o no se da. Más en concreto, explican que el único sujeto de toda actividad verdaderamente colegial es el colegio entero de los obispos, con autoridad sobre la Iglesia universal. 
Así, la Comisión Teológica Intermacional explica que "la colegialidad de los Apóstoles es universal y se entiende, en relación con el conjunto de la Iglesia, de la totalidad del cuerpo episcopal en unión con el Papa; condiciones que se verifican para el concilio ecuménico y que pueden verificarse para el Sínodo de los Obispos. La colegialidad episcopal pertenece a la estructura de la Iglesia recibida de Cristo ('jure divino'). Por el contrario, insuituciones como las conferencias episcopales (y sus agrupaciones continentales) derivan de la organización o de la forma concrela de la Iglesia ('jure eclesiástico'); el uso, respeclo de éstas, de los términos "colegio", "colegialidad" y "colegial" es, por tanto, solamente en un sentido analógico, teológicamente impropio"s.

\section{La doctrina del Concilio Vaticano II}

Frente a esta interpretación restrictiva, tenemos que volver a los textos claves del Concilio, los que propugnan las conferencias episcopales en el contexto y sobre la base de su doctrina teológica de la colegialidad de los sucesores de los apósıloles:

La potestad suprema sobre la Iglesia universal que posee cste Colegio (episcopal) se ejerce de modo solemne en el concilio ecuménico... aprobado o, al menos, aceptado como tal por el sucesor de Pedro... Esta misma poteslad colegial puede ser ejercida por los obispos dispersos por el mundo, a una con el Papa...?.

La unión colegial se manifiesta también en las mutuas relaciones de cada Obispo con las Iglesias particulares y con la Iglesia universal... Cada uno de los obispos es puesto al frente de una Iglesia particular, ejerce su poder pastoral sobre la porción del Pueblo de Dios a él encomendada, no sobre las otras Iglesias no sobre la Iglesia universal. Pero, en cuanto miembros del Colegio episcopal y como legítimos sucesores de los Apóstoles, todos y cada uno, en virtud de la institución y precepto de Cristo, están obligados a tener por la Iglesia universal aquella solicitud que, aunque no se ejerza por acto de jurisdicción, contribuye, sin embargo, en gran manera al desarrollo de la Iglesia universal... El cuidado de anunciar el Evangelio en todo el mundo pertenece al Cuerpo de los Pastores, ya que a todos ellos, en común, dio Cristo este mandato... ${ }^{10}$.

La divina Providencia ha hecho que varias Iglesias fundadas en diversas regiones por los Apóstoles y sus sucesores, al correr de los tiempos, se hayan reunido en numerosos grupos estables, orgánicamente unidos, los cuales, quedando a salvo la unidad de la fe y la única constitución divina de la Iglesia universal, tienen una disciplina propia, unos ritos litúrgicos y un patrimonio teológico y espiritual propios. Entre las cuales... las antiguas Iglesias patriarcales... Esta variedad de las Iglesias locales, tendiente a la uniDigitalizado por Biblioteca "P. Florentino Idoate, S.J."

Universidad Centroamericana José Simeón Cañas 
dad, manifiesta con mayor evidencia la catolicidad de la Iglesia indivisa. De modo análogo, las conferencias episcopales hoy en día pueden desarrollar una obra múltiple y fecunda, a fin de que el efecto colegial tenga una aplicación concreta".

Desde los primeros siglos de la iglesia, los obispos que estaban al frente de las Iglesias particulares, movidos por la comunión de fraterna caridad y por el celo de la misión universal confiada a los Apóstoles, aunaron sus fuerzas y voluntades para promover el bien común y el de las Iglesias particulares. Por cso sc organizaron los sínodos, los concilios provinciales $y$, finalmente, los concilios plenarios, en los que los obispos estatuyeron una norma igual para varias Iglesias, la cual debía observarse en la enseñanza de las verdades de la fe y en la ordenación de la disciplina eclesiástica...'2.

Señaladamente en los ticmpos modernos, no es raro que los obispos no puedan cumplir debida y fructuosamente su cargo si no unen cada día más estrechamente con otros obispos su trabajo concorde y mejor trabado. Ahora bien, dado que las conferencias episcopales -insuituidas ya en muchas naciones - han dado magnílicas prucbas de un apostolado más fecundo, piensa este Santo Concilio que en toda la tierra los obispos de la misma nación o región se agrupen en junta única, reuniéndose en fechas determinadas a fin de comunicarse las luces de la prudencia y experiencia, deliberar entrc sí y formar una santa conspiración de fuerzas para bien común de las Iglesias ${ }^{13}$.

La Conferencia episcopal es como una junta en que los obispos de una nación o territorio ejercen conjuntamente su cargo pastoral para promover el mayor bien que la Iglesia procura a los hombres, señaladamente por las formas y modos de apostolado, adaptados en debida forma a las circunstancias de tiempo'.

\section{La interpretación del Concilio}

Podemos observar que el Concilio trata de las conferencias episcopales en el contexto de su doctrina teológica de la colegialidad episcopal, sobre el horizonte más amplio de la comunión de las iglesias particulares en la Iglesia universal. Que presenta esas conferencias como una manifestación de la "unión colegial". de "la solicitud" de los "miembros del colegio episcopal" por todas las iglesias, como una manera en que "el afecto colegial" de los obispos tiene una aplicación concreta. Que las entiende en la tradición de agruparse más o menos orgánicamente varias iglesias particulares de un mismo ámbito geográfico y cultural, en analogía con las antiguas iglesias patriarcales. Que las entronca con la práctica "desde los primeros siglos de la Iglesia" de "los sínodos, los concilios provinciales y, finalmente, los concilios plenarios", en que los obispos establecen normas comunes - respecto a la fe y la disciplina - para las iglesias de una misma región ${ }^{15}$.

Digitalizado por Biblioteca "P. Florentino Idoate, S.J."

Universidad Centroamericana José Simeón Cañas 
Es verdad que en la docurina de la colegialidad episcopal, a partir de la Lumen Gentium y el Christus Dominus, hay que distinguir entre la acción colegial estricta y plena' ${ }^{16}$ y la aclividad colegial (también verdadera colegialidad) expresada con los términos "solicitud de todas las Iglesias", "unión colegial" y "afecto colegial"".

En sentido estricto, esa acción colegial es la de todo el colegio, juntamente con su cabeza, sea "solemnemente en concilio ecuménico", sea "dispersos por el mundo", y entonces esc colegio es autoridad suprema, para la Iglesia universal ${ }^{19}$. Pero se dan, y se han dado desde el el principio, otras formas de cjercicio de la colegialidad episcopal, no estricto y pleno, sino más o menos parcial o regional, formas que brotan del mismo affectus collegialis ${ }^{19}$. Este no ha de entenderse como un mero sentimiento, sino que implica la misma comunión mistérico-sacramental y carismática que se hace "efectiva" en forma plena en el concilio ecuménico.

A la luz de estos textos claves del Concilio es difícil entender cómo se haya podido sostener que las conferencias episcopales "no tienen base teológica", y que "no lienen, en cuanto tales, ninguna misión de enseñar"zo. El recién relerido sínodo extraordinario de 1985 - convocado 20 años después para "celcbrar, verificar y promover" el mismo Concilio- afirma: "La eclesiología de comunión ofrece el fundamento sacramental de la colegialidad. Por esto, la teología de la colegialidad se extiende mucho más que lo que sea mera consideración jurídica. El afecto colegial es más amplio que la colegialidad efectiva, entendida de manera meramente jurídica. El afecto colegial es el alma de la colaboración entre los obispos, sea en el campo regional, sea en el nacional o interncional... Por las conferencias episcopales, el afecto colegial es llevado a aplicación concreta". Esas pertenecen a las "diversas realizaciones parciales (de la colegialidad) que son verdaderamente signo e instrumento del afecto colegial"21.

En el mismo párafo del Sínodo de 1985 se afirma, sin embargo —siguiendo las guías de la Comisión Teológica Internacional" - que "realizaciones parciales" de la colegialidad como son las conferencias Episcopales y el sínodo de obispos, "no pueden deducirse directamente del principio teológico de la colegialidad, sino que se rigen por el derecho eclesiástico". Compartiendo el parecer de especialistas de mucho peso, consideramos que esta alimnación no es acertada $^{23}$. Pensamos que se hace aquí una aplicación equivocada, por lo rígida, de la distinción usual entre las realidades eclesiales jure divino y las jure ecclesiastico. Como si las mismas realidades teológicas de la iglesia, como entidad social visible, no se dieran siempre históricamente en formas "que se rigen por el derecho eclesiástico". Esto vale no sólo de la colegialidad episcopal, sino del bautismo y la eucaristía, de la autoridad del obispo en la iglesia particular y del papado's.

Es verdad que el mismo sínodo de 1985 , junto con afurmar de las conferenUniversidad Centroamericana José Simeón Cañas 
cias cpiscopales que "nadie duda de su uvilidad pastoral, más aún, de su necesidad en las circunstancias acluales"2" expresa también el deseo de "un estudio de su estatuto tcológico y sobre todo de la cuestión de explicar más clara y profundamente su autoridad doctrinal". Asimismo, "se recomienda un estudio que considere si el principio de subsidiaricdad vigente en la sociedad humana se puede aplicar en la Iglesia, y en qué grado y en qué sentido se pueda o deba hacer tal aplicación" ${ }^{\prime 26}$.

Al respecto, scría importante considerar que el sínodo extraordinario de 1969 - convocado en palabras del Pablo VI para "dar mayor amplitud y eficacia al carácler colcgial dcl Episcopado"27__ "partió de estos tres presupuestos compartidos por todos, aun reconociendo que ellos incluían puntos oscuros en la teoría y, sobre todo, en la práctica: $1^{9}$ ) las conferencias episcopales son expresión de la colegialidad y tienen, por esto, una sólida base teológica; $2^{9}$ ) ellas están provistas de una potestad magisterial; $3^{9}$ ) el principio de subsidiariedad ticne aplicación ucntro de la Iglesia"ª.

\section{El contexto eclesiológico de la comunión}

El Concilio en la Lumen Gentium comienza tratando el misterio de la Iglesia como sacramento de la comunión de Dios con los hombres y de los hombres entre sí, por Jesucristo cn el Espíitu, al servicio de toda la humanidad (cap. I).

A partir de este núcleo misterioso sacramental, el texto conciliar presenta la realidad histórica y social de la Iglesia tralando en primer lugar lo más fundamental de la existencia y misión cristianas, común a todos los bautizados en el pueblo de Dios (c. II). Sólo en segundo lugar pasa el mismo documento a tratar "la constitución jerárquica de la Iglesia" y las distintas funciones y formas de vida, dentro y al servicio del pueblo de Dios y su misión en el mundo (c. III).

Es conocida la importancia de este "vuelco" eclesiológico operado por el Concilio en relación a la teología católica recibida. Pero estamos lejos de sacar todas las consecuencias de este vuelco para la vida y organización de la Iglesia, particularmente en lo que toca a la corresponsabilidad y la participación.

Ya más arriba hemos reconocido que el principio teológico de la colegialidad de los sucesores de los apóstoles - del que las conferencias episcopales son una concreción parcial pero auténtica- es presentado por el mismo Concilio en el contexto de la comunión de las iglesias particulares en la Iglesia universal, y al servicio de esa misma comunión ${ }^{29}$.

El sínodo extraordinario de 1985, interpretando y prolongando el mismo Concilio, declara que "la eclesiología de comunión es una idea central y fundamental en los documentos del Concilio. Koinonia-comunión, fundadas en la Sagrada Escritura, son tenidas en gran honor en la Iglesia antigua y en las iglesias orientales haska nuestros dias. Desde el Concilio Vaticano II se ha hecho 
mucho para que se entendiera más claramente a la Iglesia como comunión y se llevara esta idea más concretamente a la vida..." 30 .

"La eclesiología de comunión es el fundamento para el orden en la Iglesia y en primer lugar para la recta relación en ella entre unidad y pluriformidad... El único y mismo Espíritu obra en muchos y en variados dones espirituales y carismas (ver 1Cor. 12, 4s); la única y misma Eucaristía se celebra en varios lugares. Por ello, la Iglesia única y universal está verderamente en todas las Iglesias particulares (ver CD 11), y éstas están formadas a imagen de la Iglesia universal, de tal manera que la una y única Iglesia católica existe en las Iglesias particulares y existe por ella (ver LG 23)"3!.

En este contexto más fundamental del misterio y la existencia sacramental de la Iglesia, sitúa el mismo sínodo el desarrollo que hemos citado más arriba. "La eclesiología de comunión ofrece el fundamento sacramental de la colegialidad... El afecto colegial es el alma de la colaboración entre los obispos, sea en el campo regional, sea en el nacional o internacional... Por las conferencias episcopales, el afecto colegial es llevado a aplicación concreta... En las conferencias episcopales, los obispos de la misma nación o territorio ejercen unidos su oficio pastoral (ver $L G 23$ y $C D 38$ )"'32.

Y luego, el mismo texto continúa: "Porque la Iglesia es comunión, la participación y la corresponsabilidad deben existir en todos sus grados... Entre el Obispo y su presbiterio existe una relación fundada en el sacramento del orden... Por ello, entre el Obispo y su presbiterio deben existir relaciones de amistad y llenas de confianza... Foméntese el espíritu de colaboración de los diáconos, y entre el Obispo y los religiosos y religiosas que trabajan en su Iglesia particular. Desde el Concilio Vaticano II hay felizmente un nuevo estilo de colaboración entre laicos y clérigos. Ese espíritu de disponibilidad con que muchísimos laicos se han ofrecido al servicio de la Iglesia debe contarse entre los mejores frutos del Concilio. En esto hay una nueva experiencia de que todos nosotros somos Iglesia... Porque la Iglesia es comunión, las nuevas "comunidades eclesiales de base", así llamadas si verdaderamente viven en la unidad de la Iglesia, son verdadera expresión de comunión e instrumento para edificar una comunión más profunda. Por ello dan una gran esperanza para la vida de la Iglesia (ver EN 58) ${ }^{\text {'33 }}$.

Finalmente, el documento termina el mismo desarrollo teologico-pastoral de esta manera: "Apoyándose en la eclesiologia de la comunión, la Iglesia católica, en tiempo del Concilio Vaticano II, asumió plenamente su responsabilidad ecuménica... El diálogo ecuménico hace que se vea a la Iglesia más claramente como sacramento de unidad. La comunión entre los católicos y otros cristianos, aunque sea incompleta, llama también a todos a la colaboración en muchos campos, y asi hace posible, de alguna manera, un testimonio común del amor

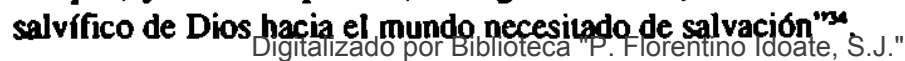

Universidad Centroamericana José Simeón Cañas 


\section{Comunión y participación desde la base.}

Si para hablar de la comunión y la participación responsable en la Iglesia el sínodo de 1985 parte del centro o de la cúspide (desde el colegio episcopal presidido por el papa, hasta las comunidades de base), los documentos más significativos del magisterio colegial latinoamericano —en Medellín y Pueblalo hacen partiendo de la periferia o la base. Y subrayan - como es normal en la perspectiva evangélica del "tercer mundo"- que esas bases de la Iglesia de Jesús se cncuentran principalmente entre las mayorías pobres de la tierra ${ }^{35}$.

Así, la Conferencia de Medellín (1968), en su capítulo de mayor densidad cclesiológica, inspirado en el Concilio, parte afirmando que "la vivencia de la comunión a que ha sido llamado, debe encontrarla el cristiano en su comunidad de base", que "la comunidad cristiana de base es el primero y fundamental núclco eclesial", у anima a que "los miembros de esa comunidades... ejerciten las funciones quc Dios les ha confiado - sacerdotal, profética y real- y hagan así de su comunidad un signo de la presencia de Dios en el mundo"36.

En forma consecuente, el documento continúa señalando que esta visión "nos lleva a hacer de la parroquia un conjunto pastoral vivificador y unificador de las comunidades de base". Nos recuerda que "la comunidad parroquial forma parte de una unidad más amplia". Sostiene con el Concilio que la diócesis, como "porción del Pueblo de Dios presidida por un obispo", constituye "una Iglesia particular, en que se encuentra y opera verdaderamente la Iglesia de Cristo que es una, santa, católica y apostólica", y que el obispo debe ser asistido por el consejo presbiteral, y ojalá por un consejo pastoral representativo del pueblo de Dios en su diversidad ${ }^{3}$.

En seguida, el mismo documento de Medellín recuerda con palabras del Concilio que "los obispos, en virud de la consagración sacramental y por la comunión jerárquica con la cabeza y los miembros del Colegio, son constituidos miembros del cuerpo episcopal... que en el magisterio y el gobiemo pastoral sucede al Colegio de los Apóstoles", y "por consiguiente deben mantenerse siempre unidos entre sí, ya que... cada uno juntamente con los otros es responsable de la Iglesia". Afurma que "la Conferencia Episcopal ha de constimir en cada país o región la expresión concreta del espíritu de colegialidad que deben animar a cada obispo"38.

Sobre la actividad de la conferencia episcopal, seflala que "ha de desenvolverse dentro de una auténtica pastoral de conjunto y con planes de pastoral que respondan siempre a la realidad humana y a las necesidades religiosas del Pueblo de Dios. Debe ser elemento de integración de las diversas diócesis, y, en especial, factor de equilibrio en la distribución de personal y de medios". Exhorta a que "procuren las conferencias Episcopales que la voz de los respeclivos presbiterios y del laicado del país lleguen fielmente hasta ellas. Asimismo, tenga

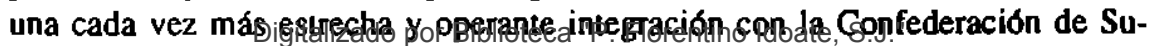


periores Mayores Religiosos. incorporándolos en el estudio, la elaboración y la ejecución de la pastoral" ${ }^{39}$.

Y para terminar este desarrollo eclesiológico-pastoral, el mismo documento pide a las conferencias episcopales que sean "los órganos de aplicación de los acuerdos de las conferencias Generales del Episcopado Latinoamericano", e indica que "para vivir profundamente cl espíritu católico estarán las conferencias Episcopales en contacto, no sólo con el Romano Ponúfice y los Organismos de la Santa Sede, sino también con las Iglesias de otros continentes, tanto para la mutua edificación de las Iglesias, como para la promoción de la justicia y de la paz en el mundo"

Por su parte la Conferencia de Puebla (1979) acentúa más la perspectiva desde la base, al arrancar más cxplícitamente su visión eclesiológica desde la lc y las prácticas devocionales y solidarias de nuestros pueblos pobres, oprimidos y creyentes. Con ese transfondo y esas raíces, reconoce con esperanza la multiplicación y maduración de las comunidades eclesiales de base $y$, desde la fe más evangélica y el amor solidario que comunican éstas, amplía su visión eclesiológica hasta la gran comunión católica servida por el colegio episcopal presidido por el papa. Lo hace en lunción de la urgente evangelización liberadora de nuestros pueblos oprimidos, y a la luz del tema profundamente tcológico que nos viene guiando en estas páginas: la vocación universal a la comunión y participación $n^{43}$.

En un pasaje clave de su documento final, Puebla afirma que "la Iglesia evangelizadora tiene una misión: predicar la conversión, liberar al hombre e impulsarlo hacia el misterio de comunión con la Trinidad y de comunión con los hermanos, transformándolos en agentes y cooperadores del designio de Dios... Cada bautizado se siente atraído por el Espíritu de Amor, quien lo impulsa a salir de sí mismo, a abrirse a los hermanos y a vivir en comunidad. En la unión entre nosotros se hace presente cl Señor Jesús resucilado que celebra su Pascua en América Lalina"‘z

Entre los diversos "centros de comunión y participación" que edifican la Iglesia y llevan adelante su misión evangelizadora, Puebla reafirma, en diversos contextos de su documento, la importancia fundamental de las Comunidades eclesiales de base: "Como pastores; queremos decididamente promover, orientar y acompañar las comunidades de base, según el espíritu de Medellín (ver "Pastoral de conjunto" 10) y los criterios de la Evangelii Nuntiandi (n. 58)"433.

Los cristianos unidos en Comunidades eclesiales de base, formentando su adhesión a Cristo, procuran una vida más evangélica en el seno del pueblo, colaboran para interpelar las raíces egoístas y consumistas de la sociedad y explicitan la vocación de comunión con Dios y con sus hermanos, ofreciendo un valioso punto de partida en la construcción de una nueva sociedad, "la civilización deliganıloräđato por Biblioteca "P. Florentino Idoate, S.J." 
Las Comunidades eclesiales de base son expresión del amor preferente de la Iglesia por el pueblo sencillo; en ellas se expresa, valora y purifica su religiosidad y se da la posibilidad concreta de participación en la tarea eclesial y en el compromiso de transformar el mundo". "El compromiso con los pobres y los oprimidos y el surgimiento de las comunidades de base, han ayudado a la Iglesia a descubrir el potencial evangelizador de los pobres, en cuanto la interpelan constantemente, llamándola a la conversión, y por cuanto muchos de ellos realizan en su vida los valores evangélicos de solidaridad, servicio, sencillez y disponibilidad para acoger el don de Dios ${ }^{45}$.

Como Medellín, Puebla destaca también, con citas del Concilio, la importancia de la Iglesia particular: en ella, "formada a imagen de la Iglesia Universal, se encuentra y opera verdaderamente la Iglesia de Cristo que es una, santa, católica y apostólica (ver $L G 23$ y $C D 11$ ). Es una porción del Pueblo de Dios, defínida por un contexto socio-cultural más amplio (que la partoquia), en el cual se encama. Su primacía en el conjunto de las comunidades eclesiales se debe al hecho de estar presidida por un obispo..."

Por ser sucesores de los Apóstoles, los obispos, a través de su comunión con el Colegio episcopal y de manera especial con el Romano Pontífice, hacen presente la apostolicidad de toda la Iglesia; garantizan la fidelidad al Evangelio; realizan la comunión con la Iglesia universal y promueven la colaboración de su Presbiterio y del desarrollo del Pueblo de Dios encomendado a sus cuidados. Responsabilidades del Obispo será discemir los carismas y fomentar los ministerios indispensables para que la diocesis crezca hacia su madurez, como comunidad evangelizada y evangelizadora, de tal manera que sea luz y fermento de la sociedad, sacramento de unidad y de liberación integral, apta para el intercambio con las demás Iglesias particulares, animada por el espíritu misionero que la haga iradiar la riqueza evangélica lograda en su interion?

Y los obispos reunidos en Puebla concluyen este capítulo de su documento comprometiéndose "para que esta colegialidad (episcopal), de la que Puebla como las dos conferencias Generales que la precedieron constituye un momento privilegiado, sea el signo más fuerte de credibilidad del anuncio y servicio del Evangelio, en favor de la comunión fraterna en toda América Latina"us.

\section{Después de Santo Domingo.}

Ese mismo compromiso de los obispos reunidos en Puebla, es el que esperdbamos - con todo el pueblo de Dios en América Latina- ver renovado y profundizado en la IV' Conferencia General de Santo Domingo. Las profundas persistentes heridas que desgarran la conviviencia humana en nuestro continente, con sus frutos amargos de marginación y violencia para las mayorías empobrecidas, hacen másiturgende ess btestimopie de defect8o fratemo y práctica cole- 
gial, que tendrían que ser características de los apóstoles de Jesucristo.

Después de Santo Domingo, nos alegramos y damos gracias porque las conferencias episcopales de nuestro continente y sus delegados - por lo menos a partir del vuelco de 1991 en el proceso preparatorio ${ }^{49}$ y especialmente en las dos semanas y media de la IV' Conferencia General - consiguieron escuchar juntos el clamor de nuestros pueblos, compartir las prácicas pastorales de sus iglesias, hacer un discemimiento comunitario de los llamados del Espíritu, y ofrecernos con su autoridad pastoral colegiada un documento linal que -aunque desigual y con algunas deficiencias importantes- nos estŕ resultando bastante realista e inspirador, en la línea evangélica de Medellín y Puebla.

Pero - lo sabemos y no lo podemos ocultar- todo eso lo lograron los obispos delegados, no con el apoyo del gobiemo central de la Iglesia católica, sino a pesar de las trabas, las nominaciones unilaterales, las censuras y discriminaciones, y los golpes de autoridad de los organismos y los personeros del Vaticano, antes y durante la IV: Conferencia. Y finalmente, la carla de Juan Pablo II que acompaña la edición oficial de las conclusiones - dirigida "a los Obispos diocesanos de América Latina" - no "aprueba" ni menos "hace suyas" esas conclusiones, sino sólo "autoriza su difusión", no al modo de Pedro que "con lirma a sus hermanos", sino al modo de un gobernante autocrático que concede a sus subaltemos poder publicar un documento de ellos. Ese documento -según la misma carta- cada obispo podrá aplicarlo o no en su diócesis, según juzgue él mismo en sus propias circunstancias. El obispo diocesano no tendrá así ninguna obligación de seguir las onientaciones de la conferencia general del episcopado latinoamericano, ni de la conferencia episcopal de su país que busque colegiadamente la aplicación de las mismas. Por otra parte, sin embargo, cada obispo en su diócesis deberá hacer su discernimiento "junto con los presbíteros... y con los demás miembros de la Iglesia parlicular que le ha sido confiada". Pero el mismo papa, aparentemente, no tiene ninguna razón suficiente para comprometerse con el discernimiento colegial de sus hermanos pastores de todo un continente -como él y con él sucesores de los apósioles- ni aunque este continente albergue de hecho a la mitad de los católicos del mundo.

Después de Santo Domingo y con sus conclusiones en la mano, realmente no vemos cómo, para la nueva evangelización y la promoción humana de nuesuros pueblos, podamos seguir reproduciendo en todos los niveles de la Iglesia calólica la cultura patriarcal y monárquica que hoy parece predominar nuevamente en su jerarquía. Sin reconocer ni asumir la cultura fraternal y participativa que nos viene no sólo de las raices culturales y religiosas de nuestros pueblos oprimidos, sino de la originalidad del evangelio de Jesús y de la experiencia cristiana que nos transmite todo el Nuevo Testamento.

Veintisiete años después del Concilio Vaticano II, y ahora con la experiencia vivida en la IV' Conferencia ${ }^{\prime}$ con las sonclusiones de la misma, pueden los 
obispos de esta patria grande latinoamericana, con la fuerza del Espiritu Santo, rescatar y actualizar el espíritu de los cambios que el mismo concilio desencadenó en la Iglesia católica, buscando hacerla menos jerarcocéntrica y clerical, y más fraternal y participativa, mediante estructuras efectivas de comunión y corresponsabilidad en todos sus niveles. Creemos que de este modo nuestros obispos podrán hacer su mejor contribución a la comunión profunda, la cultura solidaria y la promoción de estructuras participativas en y entre los pueblos de nuestro desgarrado continente.

\section{Notas}

1. Ver Concilio Vaticano II, "Lumen Gentium" (LG) 18.22 y la "Nota explicativa previa". La "polestad verdaderamence episcopal, no sólo suprema, plena y universal, sino también innediasa" del papa "sobre todos", pastores y fieles, ha sido reivindicada de nuevo con fuerza por una carta reciente de la Congregación para la Doctrina de la Fe (L'Osservasore Romano.19 de junio de 1992, p. 8. Subrayado en el texto).

2. Ver id. LG 23, 27; Christus Dominus (CD) 11, 38 (4).

3. Ver J. Rarzinger-V. Messori, Informe sobre la fe, Madrid (1985) 68-69.

4. Id. 68 (subrayados nuestros).

5. Ver especialmente LG 19-23; CD 4-7, 36-38.

6. Ver el CIC de 1983, especialmente los cc. 447 y 753.

7. Informe sobre la fe 68, citando el can. 445,4 y l. Ver CD 38 (4).

8. CTI. L'unique Eglisse du Christ, Parts (1985) 38 (subrayados y parentesis en el Lex(o). En este mismo sentido, ver el Instrumentum laboris sobre "el estanto teológico y canónico de las Conferencias Episcopales", enviado por la congregación (vaticana) de los obispos a wodas las conferencias solicitando su parecer, a principios de 1988, más de dos años después del sínodo extrordinario de 1985 que habla pedido el estudio de esta materia. Ese "Instrumento", oficialmente secteto, fue publicado en varias lenguas. Paro no se ha tenido más noticias de ese trabajo desde entonees.

9. LG 22. Ver CD 4.

10. Id. 23 Vet CD 6.

11. Id.

12. CD 36.

13. Id. 37 .

14. Id. 38 (1).

15. Práctica eclesial más antigua que los concilios ecuménicos, y tan importante en una larga tradición de las iglesias ibero-americanas, desde los concilios de Toledo (ss. V-VII) hasta las conferencias generales de Rlo. Medellín y Puebla, pasando por los varios concilios de Mexico y de Lima en la epoca colonial.

16. LG 22 y CD 4 .

17. LG 23; CD 5-6, 36-38.

18. Ver Sinodo Extraordinario de 1985, Releción final, U. C, 4 (b). Texto editado como apéndice en Documentos del Vaticano II. BAC, Madrid (1990) 699-719.

19. Ver id., 4 (a.c.). 5.

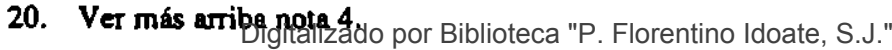
Universidad Centroamericana José Simeón Cañas 
21. Relación final Il, C, 4.

22. Ver el texto de la CTI cilado más arriba.

23. Ver, por ejemplo, el consenso expresado en el Coloquio Intemacional de Sa. lamanca, de enero de 1988, con la participación de un amplio abanico de eclesiólogos, historiadores y canonistas, de las lacultades católicas de Europa y América. Las actas del este Coloquio se recogen en H. Legrand, J. Manzanares, A. García y García (eds.). Naturaleza y fuuro de las Conferencias episcopales, Salamanca 1988. Ver especialmente las ponencias de G. Feliciani (Milán), R. Sobanski (Varsovia) y A. Artón (Roma). Ver también, del mismo A. Antón, Conferencias epis. copales iinstancias intermedias? Salamanca 1989, especialmente en su cap. II. "Fundamentación tcológica de las Con「erencias episcopales", 205-306.

24. En efccto, tampoco el papado, en su forma moderna, "puede deducirse directamenlc del principio tcológico". cл estc caso, del ministerio perino. Y de hecho, por lo que sabcmos de la hisloria, ni el mismo Pedro ni los obispos de Roma en el primer milenio fucron papas en estc sentido. Lo cual, por supuesto, no quita que el papado moderno sea una forma hislórica concrela (como tal, jure ecclesiatico) de verdadero cjercicio del ministerio peurino (jure divino).

25. Relación final II, C, 5, con referencias al CD 38 y al CIC c. 447.

26. Id. II, C B, b-c, con referencias, para el primer tema, al mismo párafo del CD y a] $\mathrm{CIC}$ cc. 447 y 753. A cstos pedidos quiere responder el Instrumentum laboris enviado de la Congregación de Obispos en 1988 (ver más arriba, nuestra nota 8). Este documento, aunque "no intenta ser definitivo" y busca respuestas de los obispos, formula de partida tesis calcgóricas por las que se pone en línea con la postura más rígida y restrictiva: 1) atribuye a las conferencias episcopales una finalidad meramente pastoral y pragmática; 2) no acepta una concepción dinámica de la colegialidad y, por lo mismo, no volora suficientemente sus realizaciones parciales o regionales; 3) niega a las mismas conferencias lodo munus magisterii. Por eso, no es de extrañar que las reacciones a este Insirumentum hayan sido muy críticas, por no encontrar en él la apertura requerida para la discusión de los temas solicitada por el sínodo de 1985. (Ver A. Anión, Conferencies episcopales..., 370-384).

27. Pablo VI, discurso de apernura, en L'Osservatore Romano del 12 de octubre de 1969. En el mismo discurso, Pablo VI da por sentado que ese objetivo del sínodo se orienta a "la aplicación del principio de subsidiariedad" en el gobiemo de la Iglesia. Y en su alocución pública del dla siguiente, el mismo papa explica que "el Concilio ha presentado la fisionomía y la función del episcopado en la Iglesia y ha aclarado su naturaleza colegial, promoviendo las Confereneias episcopales, los Sínodos y los Concilios particulares" (L'Osservalore Romana del 13-14 de octubre).

28. Testimonio del P. Antór, quien fuera secretario especial del mismo sínodo, en la presentación de su libro, op. cir. 11. Ver /d. 121-127.

29. Ver LG 13, 22-23, 25; CD 1-7, 36-38.

30. Relación final II, C. 1.

31. Id. 1-2. La reciente carta de la Congregación para la Doctrina de la Fe, citade más arriba en nuestra nota 1, complementa esa idea de este modo: "La fómula del Concilio Vaticano II: la Iglesia en y a partir de las Iglesias (LG 23), es inseparable de esta otra: las Iglesias en y a partir de la Iglesia (Jum Pablo П. Discurso a la Curia romana del 20 de diciembre de 1990)". Lo hace preocupada de corregir una Digitalizado por Biblioteca "P. Florentino Idoate, S.J."

Universidad Centroamericana José Simeón Cañas 
comprensión de la Iglesia universal como mera "suma o federación de Iglesias particulares".

32. Relación final Il, C, 4-5.

33. Id. II, C, 6 .

34. Id. II, C, 7. Ver en el mismo Concilio: LG 15; GS 40; CD 16; AG 15; UR 3-4, 12. 20-24.

35. El mismo sínodo de 1985, siempre con la preocupación de la fidelidad al Concilio, subraya también "la opción preҐeтencial por los pobres y la promoción humana" en la sección siguiente del documento cjtado, esta vez en el contexto de "la Iglesia en el mundo" (Ver Relación final II D, 3).

36. I' Conferencia General del Episcopado Latinoamericano (Medellín). Pastoral de Conjunto, nn. 10-11.

37. Id. nn. 13-18.

38. Id. $\mathrm{nn} \cdot 21-22$.

39. Id. กn. $23,25$.

40. Id. nn. 27-28.

41. Me refiero aquí no sólo (o no tanto) al capítulo del documento de Puebla "La verdad sobre la Iglesia", cuanto a la visión eclesiológica que inspira el conjunto del documento. Ver R. Muñoz, Evangelio y liberación en América Latina, la teología pasiaral de Puebla, Santiago de Chile 1980, Bogotá 1980, Sao Paulo 1981, la tercera parte y especialmente el cap. 10 "Iglesia comunión de Dios vivida en comunidades de hermanos".

42. II' Conferencia General del Episcopado Latinoamericano (Puebla), Documento final, nn. 563-564.

43. Id. n. 648 .

44. Id. n. 642.

45. Id. nn. 643, 1147.

46. Id. n. 645 .

47. Id. n. 646-647. Ver el capítulo del mismo documento de Puebla sobre el ministerio jerárquico, especialmente su "Iluminación teológico-pastoral" y las orientaciones para los propios obispos (nn. 679.707).

48. Id. n. 657.

49. Más en concteto, desde que el nuevo sectetario general del CELAM, con el concurso de los obispos secretarios de las conferencias nacionales, comenzó a tomar en serio los aportes de esas conferencias y a orientar la preparación de Santo Domingo a partir de los mismos. 